УДК 621.039 .73

\title{
Decontamination of the Equipment from Radioactive Contamination of Water after Cavitation Treatment
}

\author{
Veronika V. Shelenkova ${ }^{a, b}$, Alexey I. Kormich ${ }^{a, b}$, \\ Oleg A. Kozin ${ }^{\text {a,b }}$ and Tatiana A. Kulagina*a \\ ${ }^{a}$ Siberian Federal University \\ 79 Svobodny, Krasnoyarsk, 660041, Russia \\ ${ }^{b}$ Mining and Chemical Combine \\ 53 Lenin Str., Zheleznogorsk, 662972, Russia
}

Received 30.05.2018, received in revised form 03.07.2018, accepted 13.07.2018

In the present review are analyzed on liquid chemical methods of decontamination of surfaces with radioactive contamination. The compositions of the solutions most used at the present time for deactivation are considered. Numerical data are presented to illustrate the effectiveness of different decontamination methods. The experience of decontamination of contaminated stainless steel samples with water after cavitation treatment is described. The main results are presented.

Keywords: decontamination, surface contamination, decontamination solution, cavitation treatment, decontamination factor.

Citation: Shelenkova V.V., Kormich A.I., Kozin O.A., Kulagina T.A. Decontamination of the equipment from radioactive contamination of water after cavitation treatment, J. Sib. Fed. Univ. Eng. technol., 2018, 11(6), 732-743. DOI: 10.17516/1999494X-0088.

(C) Siberian Federal University. All rights reserved

This work is licensed under a Creative Commons Attribution-NonCommercial 4.0 International License (CC BY-NC 4.0).

* Corresponding author E-mail address: tak.sfu@gmail.com 


\title{
Дезактивация оборудования
}

\section{от радиоактивного загрязнения водой \\ после кавитационной обработки}

\author{
В.В. Шеленкова ${ }^{\mathrm{a}, \tilde{0}}$, А.И. Кормича, \\ О.А. Козин ${ }^{\mathrm{a}, \boldsymbol{0}}$, Т.А. Кулагина ${ }^{\mathrm{a}}$ \\ ${ }^{a}$ Сибирский федеральный университет \\ Россия, 660041, Красноярск, пр. Свободный, 79 \\ ${ }^{6}$ ФГУП «Горно-химический комбинат» \\ Россия, 662972, Железногорск, ул. Ленина, 53
}

В настоящем обзоре проанализированы данные о жидкостных химических способах дезактиваиии поверхностей срадиоактивным загрязнением. Рассмотрены составы растворов, наиболее используемые в настоящее время для дезактивации. Представлены численные данные, иллюстрирующие эффективность различных способов дезактивации. Описан опыт по дезактивачии загрязненных образиов из нержавеющей стали водой после кавитащионной обработки. Изложены основные результаты.

Ключевые слова: дезактивация, радиоактивное загрязнение, дезактивирующий раствор, кавитационная обработка, коэффициент дезактивации.

При эксплуатации атомных электростанций, исследовательских реакторов, кораблей и судов с ядерными транспортными установками, предприятий ядерного топливного цикла, при добыче и переработке природных ископаемых (нефти, газа, цветных металлов), а также при переработке радиоактивных отходов и отработавшего ядерного топлива происходит загрязнение оборудования, помещений и средств индивидуальной защиты персонала радиоактивными изотопами в различной химической форме и агрегатном состоянии [1].

Следует отметить, что поверхностное радиоактивное загрязнение является значимым фактором радиационного воздействия на персонал при проведении работ с использованием источников ионизирующего излучения. Поэтому для исключения дополнительных источников облучения персонала, образования радиоактивных аэрозолей и разноса радиоактивных загрязнений необходимо своевременно проводить дезактивацию оборудования, средств индивидуальной защиты и других загрязненных радиоактивными веществами поверхностей $[2,3]$.

Реализация любого способа дезактивации осуществляется в две стадии. Первая стадия процесса дезактивации заключается в преодолении связи между радиоактивным веществом (молекулы, ионы, радиоактивные частицы) и поверхностью обрабатываемого объекта. Вторая стадия включает транспортировку радиоактивного вещества с обрабатываемой поверхности загрязненного объекта. Если вторая стадия осуществляется не в полной мере, то происходит оседание радиоактивных веществ из отработанной среды обратно на поверхность и повторное загрязнение поверхности уже в процессе дезактивации. В случае глубинного загрязнения дезактивация заключается не только в преодолении связи между носителями радиоактивных загрязнений и поверхностью, но и в миграции этих загрязнений из глубины материала на поверхность и в последующем удалении их с поверхности. 
Разграничение всего процесса дезактивации на две стадии дает возможность обосновать параметры, характеризующие конкретный способ дезактивации. К таким параметрам относятся: состав дезактивирующих растворов, норма их расхода на единицу поверхности, условия применения дезактивирующих сред (скорость обработки, давление и др.) [4].

Вследствие того, что загрязнения бывают различными по природе радиоактивных изотопов, виду их соединений и уровню создаваемой ими активности, а также вследствие разнообразия поверхностей, как правило, не удается найти универсальные для всех случаев методы дезактивации [5].

В основу классификации способов дезактивации можно положить два основных принципа, определяющих агрегатное состояние дезактивирующей среды и особенности проведения процесса [6].

В зависимости от состояния среды:

- жидкостные;

- безжидкостные;

- $\quad$ комбинированные (например, дезактивация перегретым паром - безжидкостная, но после конденсации пара идет обработка жидкостью).

В зависимости от характера протекания процесса дезактивации:

- физико-механические - удаление радиоактивного загрязнения осуществляется с помощью механических или физических процессов без применения химических реагентов за исключением воды;

- $\quad$ химические - жидкостные способы, в которых основным средством воздействия является раствор химических реагентов;

- физико-химические - способы, сочетающие в себе химические, физические и механические процессы.

В группе химических методов средством воздействия на загрязненную поверхность является дезактивирующий раствор или другая среда, содержащая химические реагенты.

Использование дезактивирующих растворов относится к жидкостным методам дезактивации. Процесс дезактивации поверхностей материалов в этом случае можно выразить следующим образом:

$$
\begin{aligned}
& (\text { поверхность }+ \text { загрязняющее вещество) }+ \text { моющий раствор } \rightarrow \\
\rightarrow & \text { поверхность }+(\text { моющий раствор }+ \text { загрязняющее вещество })[7,8] .
\end{aligned}
$$

Поверхность освобождается от радиоактивного загрязнения, а радиоактивное вещество переходит в моющий раствор, т.е. происходит разрушение связи загрязнения с поверхностью. При этом состав моющего раствора подбирают таким образом, чтобы наиболее эффективно разрушить связь радиоактивных изотопов с поверхностью и предотвратить их повторную сорбцию, т.е. приведенный выше процесс должен быть направлен только слева направо.

Основные компоненты дезактивирующих растворов - вода, поверхностно-активные и комплексообразующие вещества, кислоты, щелочи, окислители и некоторые соли. В большинстве случаев используют сложные растворы, состав которых выбирают с учетом сил, удерживающих загрязняющее вещество на поверхности. Хороший эффект часто дает поочередное использование различных растворов, например кислого и щелочного, окислительного и восстановительного $[9,10]$. 
В качестве добавки, улучшающей удержание радиоактивных загрязнений в растворе, используют карбоксилметилцеллюлозу, которая образует коллоидный раствор. В табл. 1 представлены экспериментально полученные коэффициенты дезактивации загрязненных стальных поверхностей методом орошения разными растворами при одновременной обработке щеткой (60 об/мин) [6].

Растворы различного состава использовались при одной и той же норме расхода, равной 3 л/м². Применение меньшей нормы расхода, например 1 л/м², из-за неровностей обрабатываемой поверхности может привести к неполному ее смачиванию, что снизит качество дезактивации. Поэтому обычно норма расхода дезактивирующего раствора составляет $2-3$ л/ $\mathrm{M}^{2}$.

Эффективность проведения дезактивации в зависимости от времени обработки представлена в табл. 2 [4]. В этих экспериментах для дезактивации поверхности, загрязненной радионуклидами ${ }^{89} \mathrm{Sr}$ и ${ }^{91} \mathrm{Y}$, использовался $0,1 \%$-ный раствор препарата СФ-2 при норме расхода 3 л/м² при одновременном воздействии щетки (60 об/мин).

Из табл. 2 следует, что при увеличении в 8 раз времени обработки поверхности, загрязненной ${ }^{89} \mathrm{Sr}$, коэффициент дезактивации увеличивается всего на $30 \%$, что указывает на нерациональный расход дезактивирующих растворов и неэффективность затраченного на обработку времени [8].

Препараты, которые маркируются шифром СФ, предназначены для дезактивации техники, одежды и других объектов. Такие препараты поступают к потребителю в виде порошка, из которого готовятся 0,1-0,5\%-ные водные дезактивирующие растворы. Эффективность дезак-

Таблица. 1. Коэффициенты дезактивации стальной поверхности, полученные методом орошения разными растворами при одновременной обработке щеткой

Table 1. The coefficients of the decontamination of steel surfaces is obtained by spraying different solutions while treating the brush

\begin{tabular}{|l|c|}
\hline \multicolumn{1}{|c|}{ Состав раствора } & $\mathrm{K}_{\text {д }}$ \\
\hline Чистая вода & 2,5 \\
\hline $0,1 \%$ Гексаметафосфат натрия (ГМФН) & 8,7 \\
\hline $0,1 \%$ Карбоксилметилцеллюлоза (КМЦ) & 13,6 \\
\hline $0,1 \%$ Препарат СФ-2* & 13,7 \\
\hline $0,1 \%$ ГМФН + 0,1 \% (КМЦ) & 14,1 \\
\hline
\end{tabular}

Таблица 2. Коэффициент дезактивации поверхности 0,1\%-ным раствором СФ-2 в зависимости от времени

Table 2. Coefficient of decontamination of the surface of a $0.1 \%$ solution of SF-2 depending on time

\begin{tabular}{|c|c|c|c|c|}
\hline \multirow{2}{*}{$\begin{array}{c}\text { Загрязняющий } \\
\text { радионуклид }\end{array}$} & \multicolumn{4}{|c|}{ Время обработки, с } \\
\hline $\mathrm{Sr}^{89}$ & 2,7 & 5,5 & 16,5 & 22,5 \\
\hline $\mathrm{Y}^{91}$ & 22 & 23 & 27 & 29 \\
\hline
\end{tabular}




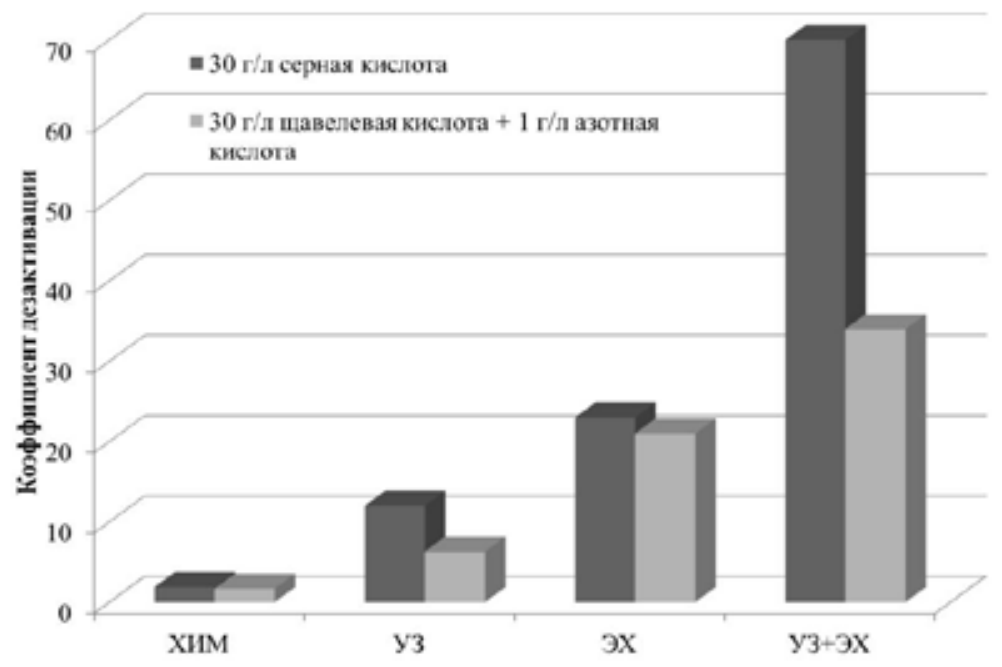

Рис. 1. Результаты обработки натурных радиоактивно загрязненных (цезий-137) образцов нержавеющей стали [11]

Fig. 1. The results of processing of field contaminated (cesium-137) of the samples of stainless steel [11]

тивации химическими растворами можно увеличить интенсификацией процесса [11-14], например приложением разности потенциалов [15].

Установлено, что при этом процесс удаления радиоактивных веществ с поверхности металла ускоряется в несколько раз [11]; кроме того, частичному растворению подвергается и сам металл, что обеспечивает удаление глубоко продиффундировавших радиоактивных загрязнений. Тем не менее наличие или образование в процессе электролиза на поверхности металла труднорастворимых оксидных пленок замедляет анодное растворение металлов, вплоть до его полного прекращения (явление пассивации), и снижает эффективность дезактивации. Группой авторов во главе с А.А. Акатовым, Ю.С. Коряковским были проведены эксперименты с использованием натурных радиоактивно загрязненных образцов нержавеющей стали. Результаты эксперимента представлены на рис. 1. Основной измеряемой величиной являлся коэффициент дезактивации. Обработка проводилась в течение 20 мин при комнатной температуре. Низкий уровень загрязнения предоставленных образцов определил невысокие коэффициенты дезактивации: в случае совместной ультразвуковой и электрохимической обработки за 20 мин практически удалось достигнуть фоновых значений [11].

В данной работе описан опыт по реализации жидкостного метода дезактивации загрязненных образцов нержавеющей стали с использованием воды после кавитационной обработки. Опыт был реализован на промплощадке ФГУП «Горно-химический комбинат» в августе 2017 г.

\section{Материалы и методы исследований}

Объект исследования - образцы нержавеющей стали, которые были получены путем фрагментации трубы, находившейся в технологическом процессе радиохимического производства Горно-химического комбината с 1967 по 2010 гг. Размер фрагментов составил Ø50 × 3, $L=100$ мм.

$$
-736-
$$


Поскольку представленные образцы имеют радиоактивное загрязнение, работы по дезактивации проводились с обязательным использованием средств индивидуальной защиты. Комплект СИЗ включал: комплект спецодежды (нательное белье х/б, комбинезон, чепчик, ботинки), полухалат пластикатовый, нарукавники пластикатовые, перчатки х/б, перчатки резиновые, лепесток ШБ-200. Перед дезактивацией были измерены следующие радиационные параметры: гамма-излучение от образца, поверхностное радиоактивное бета-загрязнение. Измерения проводились дозиметром-радиометром МКС-АТ1117М с блоками детектирования БДПБ-01, БДКГ03. Дозиметр-радиометр МКС-АТ1117М представляет собой многофункциональное носимое средство измерения с цифровой индикацией показаний, включающее в себя блок обработки и индикации информации (БОИ или БОИ2) со встроенным газоразрядным счетчиком и внешние интеллектуальные блоки детектирования различного назначения. Номер в государственном реестре РФ - 29551-13. Технические характеристики блоков детектирования представлены в табл. 3. Для изучения радионуклидного состава представленных образцов использовали спектрометр Inspector-1000 со сцинтилляционным детектором NaI: время набора спектра 1000 с. Для обработки спектров использовалось программное обеспечение Genie-2000.

Для измерения гамма-излучения был использован прямой метод измерения в соответствии с методикой измерения «Мощность эквивалентной дозы гамма- и нейтронного излучений, плотность потоков частиц ионизирующего излучения» (МВИ 01-13.018-2016). Для оценки поверхностного радиоактивного бета-загрязнения использована методика измерения «Радиоактивное загрязнение поверхностей альфа- и бета-активными веществами» (МВИ 01-13.0192016). Данные методики аттестованы Федеральным агентством по техническому регулированию и метрологии, внедрены и используются на Горно-химическом комбинате. Измерение поверхностного бета-загрязнения проводили методом сухого мазка. Для этого были приготовлены листки фильтровальной бумаги размером $5 \times 5$ см. Процедура отбора проб методом сухого мазка состоит в протирании загрязненного участка фильтровальной бумагой. Затем взятый мазок измеряют, тем самым получая значение снимаемого (нефиксированного) поверхностного загрязнения.

Всего было дезактивировано 10 образцов. Первый этап эксперимента включал дезактивацию пяти образцов с использованием дезактивирующих растворов на основе обычной воды.

Таблица 3. Технические характеристики блоков детектирования

Table 3. Technical characteristics of detection units

\begin{tabular}{|l|c|}
\hline \multicolumn{2}{|c|}{ Блок детектирования БДПБ-01 } \\
\hline Диапазон измерения плотности потока бета-частиц & $1 \div 5 \cdot 10^{5} \mathrm{мин}^{-1} \mathrm{~cm}^{-2}$ \\
\hline Диапазон регистрируемых энергий & $0,155 \div 3,5 \mathrm{MэB}$ \\
\hline Пределы допускаемой основной относительной погрешности & $\pm 20 \%$ \\
\hline \multicolumn{2}{|c|}{ Блок детектирования БДКГ-03 } \\
\hline $\begin{array}{l}\text { Диапазон измерения мощности амбиентного эквивалента дозы } \\
\text { гамма-излучения }\end{array}$ & $0,03 \div 300$ мкЗв·- ${ }^{-1}$ \\
\hline Диапазон регистрируемых энергий & $0,05 \div 3 \mathrm{MэВ}$ \\
\hline Пределы допускаемой основной относительной погрешности & $\pm 20 \%$ \\
\hline
\end{tabular}


Второй этап - дезактивация остальных пяти образцов водой, прошедшей кавитационную обработку, без добавления химических реагентов. В табл. 4 представлены результаты измерения радиационных параметров образцов до дезактивации.

На рис. 2, 3 изображены набранные спектры. Видим, что загрязнение образцов обусловлено в основном Cs-137.

\section{Результаты экспериментального исследования}

Условия проведения эксперимента: температура $24,7{ }^{\circ} \mathrm{C}$, давление 749 мм рт. ст., влажность $61 \%$. Измерения параметров микроклимата проводили термогигрометром ИВТМ-7М. Для дезактивации образцов были использованы следующие дезактивирующие растворы.

1. Щелочной $\left(\mathrm{NaOH}, \mathrm{KMnO}_{4}\right)$. Состав: вода $-99,3 \%, \mathrm{NaOH}-0,5 \%, \mathrm{KMnO}_{4}-0,2 \%$.

2. Волгонат. Состав: вода - 99,3 \%, сульфонол $-0,5 \%, \mathrm{H}_{2} \mathrm{C}_{2} \mathrm{O}_{4}-0,2 \%$.

3. Средство для дезактивации Фон-П. Состав: вода дистиллированная, изопропиловый спирт, полифосфат натрия, щавелевая кислота, сульфонол, смачиватель ОП-7, кислота ОЭДФ.

Таблица 4. Результаты измерения радиационных параметров до дезактивации

Table 4. The results of measurements of radiological parameters before deactivation

\begin{tabular}{|c|c|c|c|}
\hline № образца & $\begin{array}{c}\gamma, \text { мк3в/ч } \\
\text { МКС-АТ1117M }\end{array}$ & $\begin{array}{c}\beta, \text { част/см²·мин } \\
\text { МКС-АТ1117M }\end{array}$ & $\begin{array}{c}\mathrm{A}_{\gamma} \text { по Сs } \\
\text { Inspector-1000 }\end{array}$ \\
\hline Образец № 1 & 5,3 & 13000 & 5262 \\
\hline Образец № 2 & 4,2 & 27000 & 13125 \\
\hline Образец № 3 & 3,3 & 20000 & 7301 \\
\hline Образец № 4 & 3,0 & 38000 & 13037 \\
\hline Образец № 5 & 3,0 & 5000 & 3766 \\
\hline
\end{tabular}

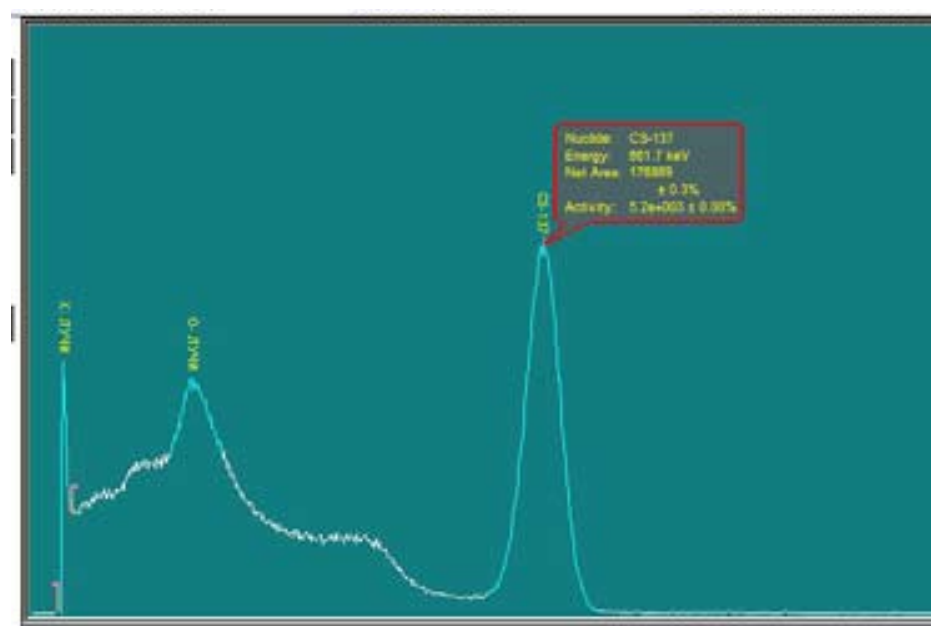

Рис. 2. Образец № 1 до дезактивации

Fig. 2. Sample No. 1 before decontamination 


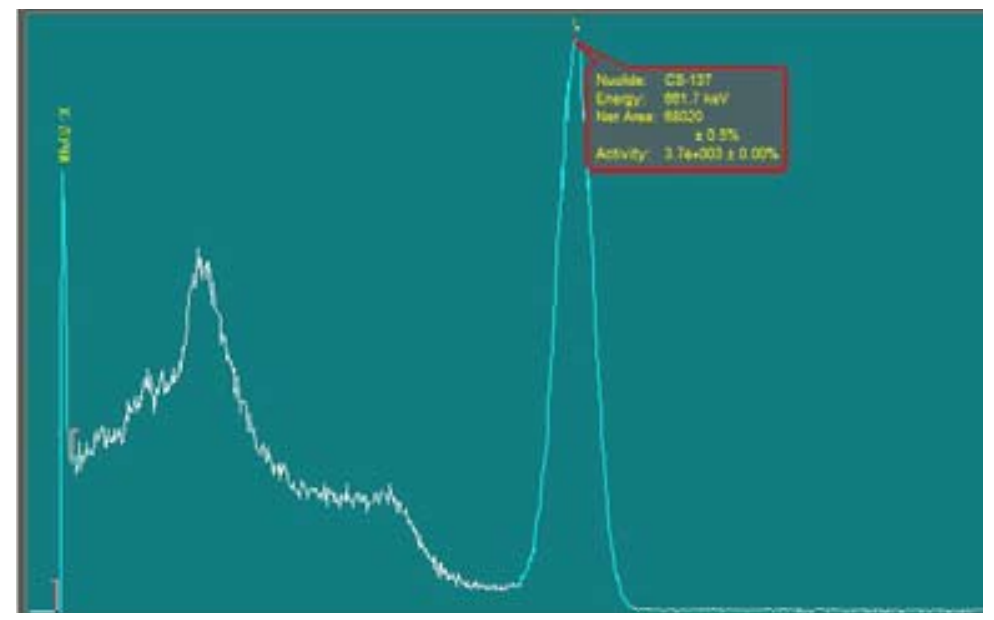

Рис. 3. Образец № 5 до дезактивации

Fig. 3. Sample No. 5 before decontamination

Образцы № 1 и № 2 были погружены в щелочной раствор. Образцы № 3 и № 4 были погружены в волгонат. Объем раствора 1,5 л, время замачивания 1,5 ч. Образец № 5 был погружен в обычную воду. Объем воды 1,5 л, время замачивания 1,5 ч.

После замачивания образцов на 1,5 ч, используя ветошь, проводим дезактивацию растиранием раствора. Время воздействия 5 мин. Дезактивацию образца № 5 проводили с использованием средства для дезактивации Фон-П. Для этого на загрязненную поверхность образца наносили пену, после ее оседания остатки вместе с десорбированным загрязнением удаляли ветошью и смывали водой. К достоинствам дезактивации растиранием раствора можно отнести возможность проводить обработку оборудования сложной формы и труднодоступных участков, к недостаткам - применение ручного труда в радиационно опасных условиях, как следствие - дозовые нагрузки на персонал.

Для определения эффективности дезактивации повторно измерили радиационные параметры образцов. В табл. 5, 6 представлены результаты измерений радиационных параметров образцов после дезактивации.

Для расчета коэффициента дезактивации использовали формулу

$$
K_{\text {д }}=\frac{A_{1}}{A_{2}},
$$

где $A_{1}$ - активность образца до дезактивации; $A_{2}$ - активность образца после дезактивации. Рассчитанные коэффициенты дезактивации даны в табл. 7.

Из полученных данных видно, что наиболее эффективным способом дезактивации является дезактивация с использованием волгоната (образцы № 3 и № 4). Низкую эффективность дезактивации образца № 5 можно объяснить тем, что образец был погружен в обычную воду без добавления дополнительных химических реагентов. Различие в рассчитанных значениях коэффициента дезактивации может быть обусловлено неравномерным распределением загрязнения по поверхности, а также погрешностью измерений.

$$
-739-
$$


Таблица 5. Результаты измерения активности образцов с использованием спектрометра Inspector-1000

Table 5. Results of measurement of the activity of samples using a spectrometer Inspector-1000

\begin{tabular}{|c|c|c|c|}
\hline \multirow{2}{*}{ № образца } & $\begin{array}{c}\mathrm{A}_{\gamma} \text { по Сs137, Бк } \\
\text { Inspector-1000 }\end{array}$ & $\begin{array}{c}\text { А по Сs137, Бк } \\
\text { Inspector-1000 }\end{array}$ & $\begin{array}{c}\text { Коэффициент } \\
\text { дезактивации }\end{array}$ \\
\cline { 2 - 4 } & $\begin{array}{c}\text { Показания прибора до } \\
\text { дезактивации }\end{array}$ & $\begin{array}{c}\text { Показания прибора после 1 цикла } \\
\text { дезактивации }\end{array}$ & 3,96 \\
\hline Образец № 1 & 5262 & 1328 & 41,6 \\
\hline Образец № 2 & 13125 & 315 & 107,4 \\
\hline Образец № 3 & 7301 & 68 & 106,8 \\
\hline Образец № 4 & 13037 & 122 & 1,4 \\
\hline Образец № 5 & 3766 & 2760 & \\
\hline
\end{tabular}

Таблица 6. Результаты измерения плотности потока бета-частиц образцов после дезактивации

Table 6. Results of measurement of beta-particle flux density of samples after decontamination

\begin{tabular}{|c|c|c|c|}
\hline \multirow{2}{*}{ № образца } & $\begin{array}{c}\beta, \text { част/см²·мин } \\
\text { МКС-АТ1117М }\end{array}$ & $\begin{array}{c}\beta, \text { част/см }{ }^{2} \cdot \text { мин } \\
\text { МКС-АТ1117М }\end{array}$ & $\begin{array}{c}\text { Коэффициент } \\
\text { дезактивации }\end{array}$ \\
\cline { 2 - 3 } & $\begin{array}{c}\text { Показания прибора до } \\
\text { дезактивации }\end{array}$ & $\begin{array}{c}\text { Показания прибора после 1 цикла } \\
\text { дезактивации }\end{array}$ & 6,2 \\
\hline Образец № 1 & 13000 & 2071 & 29,8 \\
\hline Образец № 2 & 27000 & 906 & 122,7 \\
\hline Образец № 3 & 20000 & 163 & 150,2 \\
\hline Образец № 4 & 38000 & 253 & 2,2 \\
\hline Образец № 5 & 5000 & 2283 & \\
\hline
\end{tabular}

Таблица 7. Рассчитанные коэффициенты дезактивации

Table 7. The coefficients of decontamination

\begin{tabular}{|c|c|c|}
\hline № образца & $\begin{array}{c}K_{\text {д1 }} \\
\text { Inspector-1000 }\end{array}$ & $\begin{array}{c}K_{\text {Д2 }} \\
\text { МКС-AТ1117M }\end{array}$ \\
\hline Образец № 1 & 3,96 & 6,2 \\
\hline Образец № 2 & 41,6 & 29,8 \\
\hline Образец № 3 & 107,4 & 122,7 \\
\hline Образец № 4 & 106,8 & 150,2 \\
\hline Образец № 5 & 1,4 & 2,2 \\
\hline
\end{tabular}

Дезактивация образцов №№ 6-10 проводили с использованием воды, прошедшей кавитационную обработку. Радиоактивное загрязнение этих образцов также обусловлено Сs ${ }^{137}$. На рис. 4 отражен набранный спектр.

Образцы были погружены в воду, прошедшую кавитационную обработку [2]. Время замачивания 1,5 ч. Затем, используя ветошь, провели дезактивацию методом растирания. Время 


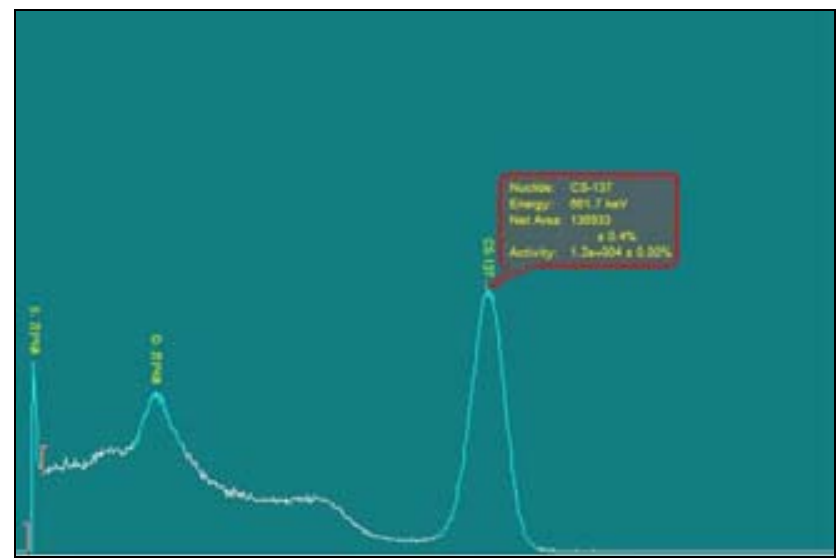

Рис. 4. Образец № 8 до дезактивации

Fig. 4. Sample No. 8 before decontamination

Таблица 8. Результаты погружной дезактивации в кавитационно-активированной воде

Table 8 . Results of submersible decontamination in cavitation-activated water

\begin{tabular}{|c|c|c|c|c|c|c|}
\hline \multirow{2}{*}{ № образца } & $\begin{array}{l}\beta, \text { част } / \mathrm{cm}^{2} \cdot \text { мин } \\
\text { МКС-АТ } 1117 \mathrm{M}\end{array}$ & $\begin{array}{l}\beta, \text { част } / \text { см }^{2} \cdot \text { мин } \\
\text { МКС-АТ } 1117 \mathrm{M}\end{array}$ & \multirow{2}{*}{$K_{\text {д }}$} & $\begin{array}{l}\mathrm{A}_{\gamma} \text { по } \mathrm{Cs}^{137}, \text { Бк } \\
\text { Inspector-1000 }\end{array}$ & $\begin{array}{l}\mathrm{A}_{\gamma} \text { по } \mathrm{Cs}^{137}, \text { Бк } \\
\text { Inspector-1000 }\end{array}$ & \multirow{2}{*}{$K_{\text {д }}$} \\
\hline & $\begin{array}{c}\text { Показания } \\
\text { прибора до } \\
\text { дезактивации }\end{array}$ & $\begin{array}{c}\text { Показания } \\
\text { прибора после } \\
\text { дезактивации }\end{array}$ & & $\begin{array}{c}\text { Показания } \\
\text { прибора до } \\
\text { дезактивации }\end{array}$ & $\begin{array}{c}\text { Показания } \\
\text { прибора после } \\
\text { дезактивации }\end{array}$ & \\
\hline Образец № 6 & 39000 & 2600 & 15 & 29532 & 1685 & 17,5 \\
\hline Образец № 7 & 35000 & 3270 & 10,7 & 18779 & 1564 & 12,0 \\
\hline Образец № 8 & 14000 & 1100 & 12,7 & 11733 & 820 & 14,3 \\
\hline Образец № 9 & 36000 & 3420 & 10,5 & 27452 & 1705 & 16,1 \\
\hline Образец № 10 & 5600 & 1030 & 5,4 & 8779 & 756 & 11,6 \\
\hline
\end{tabular}

воздействия 5 мин. Для определения эффективности дезактивации повторно были измерены радиационные параметры образцов и рассчитан коэффициент дезактивации. Полученные результаты представлены в табл. 8 .

Полученные данные показывают большую эффективность дезактивации образцов кавитационно-активированной водой по сравнению с обычной. Так, коэффициент дезактивации образца № 5 после замачивания образца в обычной воде составил 1,4 (см. табл. 5). При дезактивации образцов кавитационно-активированной водой значения коэффициента дезактивации находятся в диапазоне от 11,6 до 17,5 (табл. 8).

\section{Заключение}

Анализируя результаты эксперимента, можно прийти к следующим выводам. Дезактивация образцов водой после кавитационной обработки более эффективна, чем дезактивация обычной водой. Также стоит отметить, что эффективность дезактивации кавитационно- 
активированной водой сопоставима с результатами дезактивации щелочным раствором. Исходя из полученных результатов можно предположить, что дезактивирующие растворы на основе кавитационно-активированной воды будут более эффективны, чем растворы на основе обычной воды. Поэтому предлагается продолжить эксперимент по дезактивации загрязненных образцов дезактивирующими растворами на основе кавитационно-активированной воды.

При получении положительных результатов эксперимента использование кавитационноактивированной воды позволит улучшить качество дезактивации. Следовательно, уменьшит количество используемых химических реагентов, а также объем жидких радиоактивных отходов, что способствует снижению дозовых нагрузок на персонал и воздействия радиоактивных отходов на окружающую среду.

\section{Список литературы}

[1] Кулагина Т.А., Шеленкова В.В. Способы дезактивации поверхностей с радиоактивным загрязнением. Журнал СФУ. Техника и технологии, 2017, 10(3), 352-363 [Kulagina T.A., Shelenkova V.V. Methods of decontamination of surfaces contamination. J. Sib. Fed. Univ. Eng. technol., 2017, 10(3), 352-363 (in Russian)].

[2] Балонов М.И., Голиков В.Ю., Пархоменко В.И., Пономарев А.В. Дезактивация населенных пунктов Брянской области после аварии на Чернобыльской АЭС, Радиационная гигиена. 2014, 7, 1, 5-15 [Balonov M.I., Golikov V.Yu., Parkhomenko V.I., Ponomarev A.V. Decontamination of settlements of the Bryansk region after the Chernobyl accident, Radiation Hygiene. 2014, 7, 5-15 (in Russian)].

[3] Клочков В.Н., Рубцов В.И. Дезактивация средств индивидуальной защиты при ликвидации последствий радиационной аварии: опыт Чернобыля и его применение в современных условиях, Медицинская радиология и радиационная безопасность, 2016, 4, 19-23 [Klotchkov V.N., Rubtsov V.I. Decontamination of personal protective equipment at liquidation of consequences a radiological accident: Chernobyl experience and its application in modern conditions, Nuclear Medicine and Radiation Safety, 2016, 4, 19-23 (in Russian)].

[4] Зимон А.Д., Пикалов В.К. Дезактиваиия. М.: Атомиздат, 1994. 336 с. [Zimon A.D., Pikalov V.K. Decontamination M.: Atomizdat, 1994. 336 p. (in Russian)].

[5] Омельянюк М.В. Дезактивация нефтепромыслового оборудования от природных радионуклидов, Экология и промышленность России, 2013, 2, 1-9 [Omelyanyuk M.V. Decontamination of oilfield equipment from natural radionuclides. Ecology and Industry of Russia 2013, 2, 1-9 (in Russian)].

[6] Коряковский Ю.С., Акатов А.А., Доильницын В.А. Дезактивация: обеспечение радиационной безопасности на предприятиях ядерной отрасли: учебник. СПб.: СПбГТИ(ТУ), 2010. 150 c. [Koryakovsky Y.S., Akatov A.A., Doilnitsyn V.A. Decontamination: radiation safety at the enterprises of the nuclear industry: textbook, SPb.: SPbSTI (TU), 2010. 150 p. (in Russian)].

[7] Городинский С.М., Гольдштейн Д.С. Дезактивачия полимерных материалов. М.: Атомиздат, 1975. 224 с. [Gorodinskiy S.M., Goldstein D.S. Decontamination of polymeric materials. М.: Atomizdat, 1975. 224 p. (in Russian)]. 
[8] Анисимов А.И., Осминин В. Исследования по химии и технологии и применению радиоактивных веществ. Л.: Изд. ЛТИ, 1988. С. 94-98. [Anisimov A.I., Osminin V. Studies on Chemistry and Technology and the use of radioactive substances. L.: Publishing LIT, 1988. 94-98 (in Russian)].

[9] Шафикова С.Н., Шафиков Д.Н., Белозуб А.Н. Оценка применимости современных моющих средств для целей дезактивации. Вопросы радиационной безопасности, 2012, 2, 11-18 [Shafikova S.N. Shafikov D.N., Belozub A.N. Evaluation of the applicability of modern detergents for decontamination purposes, Radiation Safety Questions. 2012, 2, 11-18 (in Russian)].

[10] Новый справочник химика и технолога. Радиоактивные вещества. Вредные вещества. Гигиенические нормативы. СПб.: АНО НПО «Профессионал», 2004. 1142 с. [The new directory chemist and technologist. Radioactive substances. Harmful substances. Hygienic standards. SPb.: ANO NPO "Professional", 2004. 1142 p. (in Russian)].

[11] Акатов А.А., Коряковский Ю.С., Доильницын В.А.и др. Глубокая дезактивация металлов с применением ультразвука и электрохимических реакций, Aктуальные вопросы ядерно-химических технологий и экологической безопасности: Сб. трудов НПК, 2016. 57-60 [Akatov A.A., Koryakovsky Y.S., Doilnitsyn V.A. etc. Deep decontamination of metal with ultrasound and electrochemical reactions, Proceedings of the scientific-practical conference "Actual problems of nuclear and chemical technologies and ecological safety”, 2016, 57-60 (in Russian)].

[12] Савкин А.Е., Карлина О.К., Васильев А.П. и др. Испытания ультразвуковой установки для дезактивации металлических радиоактивных отходов, Безопасность окружающей среды, 2007, 3, 38-41 [Savkin A.E., Carlin D.C., Vasiliev A.P. etc. Tests ultrasonic device for decontamination of metal radioactive waste. Safety Environmen, 2007, 3, 38-41 (in Russian)].

[13] Коряковский Ю.С., Доильницын В.А., Акатов А.А. Применение усовершенствованных пленкообразующих полимерных композиций для повышения эффективности дезактивации металлов, Сборник статей по материалам научно-практической конференции «Актуальные вопросы ядерно-химических технологий и экологической безопасности», г. Севастополь, 2016. 142-145 [Koryakovsky Y.S., Doilnitsyn V.A. Akatov A.A. The use of advanced film-forming polymer compositions for increasing the efficiency of decontamination of metals, Collected articles on materials of scientific-practical conference "Actual problems of nuclear and chemical technologies and ecological safety" Sevastopol, 2016. 142-145 (in Russian)].

[14] Аксенов В.И., Кадников А.А., Шастин А.Г. и др. Новые способы применения ультразвука для дезактивации оборудования ЯЭУ, Вопросы радиационной безопасности. 2012, 1, 10-15 [Aksyonov V.I., Kadnikov A.A., Shastin A.G. etc. New ways to use of ultrasound for the decontamination of equipment NPP, Radiation Safety Questions. 2012, 1, 10-15 (in Russian)].

[15] Лебедев Н.M., Арефьева А.Н., Васильев А.П.и др. Универсальный промышленный комплекс для дезактивации металлических радиоактивных отходов с использованием ультразвука и электрохимии, Сборник трудов IV Международной научно-технической конференции «Инновационные проекты и технологии ядерной энергетики». М., 2016. 489-494 [Lebedev N.M., Aref'eva A.N., Vasiliev A.P. etc. Universal industrial complex for decontamination of metal radioactive waste using ultrasound and Electrochemistry, Proceedings of the IV International scientific-technical conference "Innovation projects and technologies of nuclear power". Moscow, 2016. 489-494 (in Russia)]. 